\title{
A MEGAGAMETOPHYTE ANALYSIS OF GENETIC LINKAGE IN PITCH PINE (PINUS RIGIDA MILL.)
}

\author{
R. P. GURIES,* S. T. FRIEDMAN† and F. T. LEDIG \\ School of Forestry and Evironmental Studies, Yale University, New Haven, \\ Connecticut 065II
}

Received 4.xi.77

\begin{abstract}
SUMMARY
The haploid state of conifer megagametophyte tissue provides a means of testing for genetic linkage among allozyme loci in conifers. Using pitch pine trees (Pinus rigida Mill.), which were previously determined to be heterozygous for certain allozymes, we have been able to detect linkage among several pairs of loci. One such pair, GOT-1 and GPI-2, is tightly linked showing a recombination frequency of 4 per cent. Four other pairs appear to be linked with recombination frequencies at the margin of detectability, $38-40$ per cent, but tree-to-tree variation makes positive determination difficult for less tightly linked loci. Such variation may be due to small sample sizes and presence of inversion polymorphisms. These results are the first report of tight linkage in a forest tree and represent a start in mapping the conifer genome.
\end{abstract}

\section{INTRODUCTION}

THE linkage of genes on the same chromosome is a well-known genetic phenomenon, and detailed linkage maps exist for a number of well-studied animals and plants (Green, 1970; Neuffer and Coe, 1970; Lalley, 1977; MacIntyre and O'Brien, 1977). In general, such maps are constructed for organisms which are amenable to controlled breeding experiments, possess a relatively short life cycle, a low chromosome number, and an abundance of natural or induced variation; man is one notable exception. Organisms such as forest trees, which generally do not possess such experimentally facile features, have been poorly studied in this regard. Attempts at detecting linkage among polymorphic loci have been reported in a few tree species, generally with negative results (Bergmann, 1974; Lundkvist, 1974; Simonsen and Wellendorf, 1975).

The study of linkage in multilocus systems has received new attention due to the ease with which large numbers of allozyme polymorphisms can be analysed, and because of interest in questions concerning the distribution and maintenance of genic variation in natural populations (Langley et al., 1974; Zouros et al., 1974). It is of interest, for example, to determine whether non-random associations of allozymes exist, and whether epistatic selection is responsible for maintaining these blocks of interacting sets of loci (Clegg et al., 1972).

Megagametophyte tissue of conifer seed offers an advantage in studies of genic segregation seldom found in diploid organisms, namely, its haploid nature. Each megagametophyte represents a single meiotic product. Using electrophoretic techniques, it is possible to discriminate between

* Present address : Department of Forestry, Russell Laboratories, University of Wisconsin, Madison, Wisconsin 53706.

$\dagger$ Present address: College of Agriculture and Life Sciences, University of New Hampshire, Durham, New Hampshire 03824. 
heterozygous and homozygous trees by analysing a number of seed from each individual. Deviations from independent assortment can be detected by analysing seed from trees which are heterozygous at two or more loci. In a previous paper, we reported results of tests involving certain pairs of loci, none of which exhibit linkage (Guries and Ledig, 1978). Based upon a more extensive assessment, we now report the linkage of allozyme loci in pitch pine (Pinus rigida Mill.). Trees have been recalcitrant in regard to providing examples of classical genetic segregation and assortment; this is the first report of tight linkage in a forest tree species.

\section{Materials and methods}

As part of a population genetics study of pitch pine, we analysed a number of allozyme loci, including two loci each of 6-phosphogluconate dehydrogenase (6-PGD-1 and 2), leucine aminopeptidase (LAP-1 and 2), malate dehydrogenase ( $\mathrm{MDH}-1$ and 2), glutamate oxalate transaminase (GOT-1 and 2), and one each of aconitase (ACO), isocitrate dehydrogenase (IDH), and acid phosphatase (AP). Conditions for horizontal starch gel electrophoresis were reported elsewhere (Guries and Ledig, 1978) for all systems except acid phosphatase. Acid phosphatase was run on buffer system 4 of Guries and Ledig (1978) and stained according to Scandalios (1969), except that the stain buffer was adjusted to $p \mathrm{H} 5.0$.

From a large number of single-tree collections of pitch pine, we selected nine trees which were previously determined to be heterozygous for four or more enzyme loci. As several enzyme systems can be stained with slices from the same starch gel, comparisons among several loci can be made in pairwise fashion for the same set of megagametophytes. Zymograms were analysed for agreement to a model of independent assortment. For all enzyme systems studied thus far, allozyme variants segregate randomly in a fashion suggestive of control by co-dominant alleles (Guries and Ledig, 1978).

\section{Results AND Discussion}

A total of 53 pairs of allozyme loci were compared in at least one tree; 13 of these pairs were subsequently compared in at least one additional tree (table 1). One pair of loci, GPI-2 and GOT-1 was found to be tightly linked with an average recombination frequency estimated to be 4 per cent (table 1). These two loci appear to be linked in Pinus ponderosa Laws. as well (D. O’Malley, Br. Columbia For. Serv., personal communication). Deviations from independent assortment were detected for four other pairs of loci, 6PGD-1 and ACO, PGM-1 and IDH, LAP-1 and ACO, and LAP-2 and IDH. The recombination frequencies for these pairs of loci were estimated to be $40,39,38$ and 39 per cent respectively (table 1). Bergmann (1974) reported $42 \%$ recombination between two ecterase loci in Picea abies (L.) Karst.

Because pines have a haploid complement of 12 chromosomes and chiasma frequency of c. 2.5 per bivalent (Sax, 1933; Saylor and Smith, 1966), gene loci are expected to fall into approximately $12 \times 2.5$ or 30 linkage groups. Therefore, the probability of detecting linkage (i.e., less than 50 per cent recombinants) is $1 / 30$, or for the 53 pairs of loci, c. 1.8 linked 

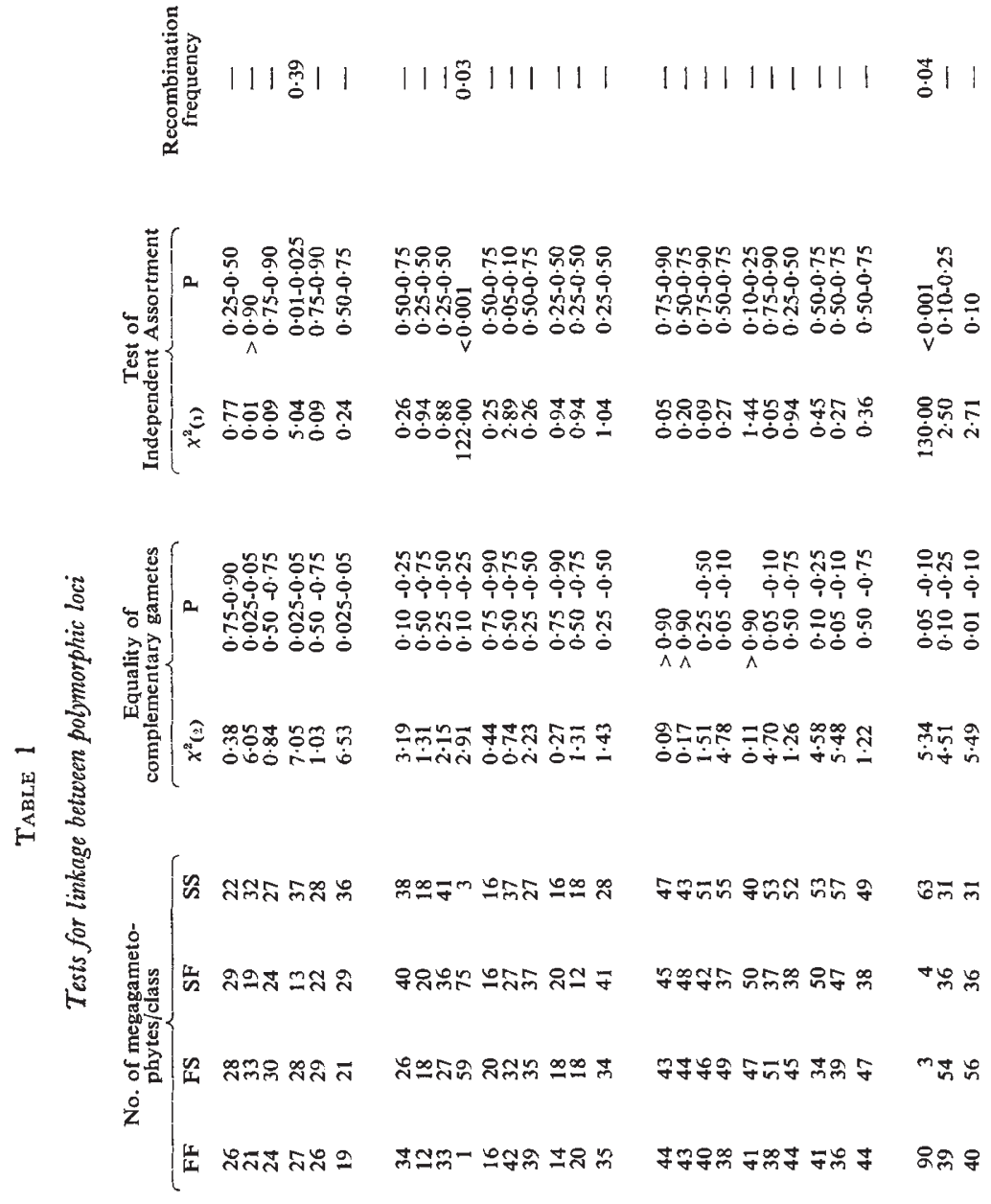

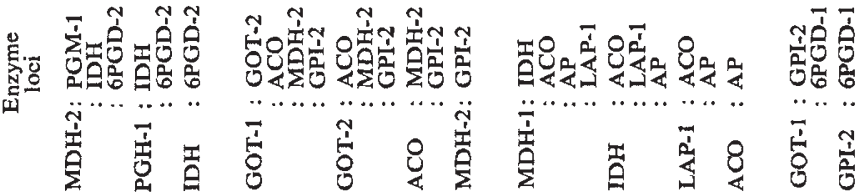

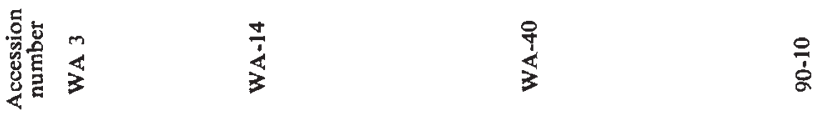




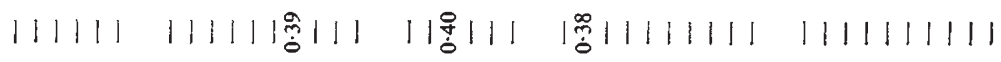

\begin{tabular}{|c|c|c|c|c|}
\hline & 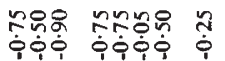 & 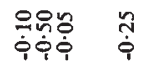 & 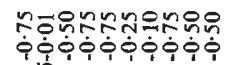 & \\
\hline & 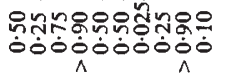 & 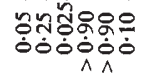 & 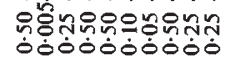 & \\
\hline Ẽ & +a. & & 8 & \\
\hline
\end{tabular}

\begin{tabular}{|c|c|c|c|c|}
\hline 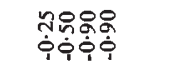 & 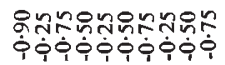 & 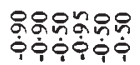 & 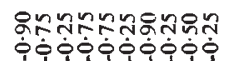 & 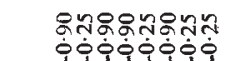 \\
\hline 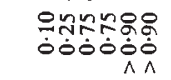 & $\begin{array}{l}\text { nopnonoำn } \\
\text { ódódódón }\end{array}$ & 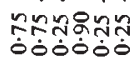 & $\begin{array}{l}\text { nopophono } \\
\text { obodobododo }\end{array}$ & 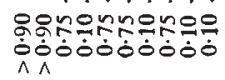 \\
\hline 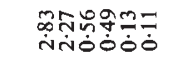 & 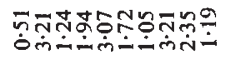 & 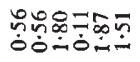 & 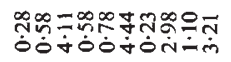 & 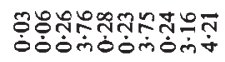 \\
\hline ์ที่ำの & 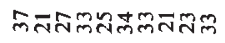 & ำกสำก & 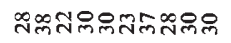 & 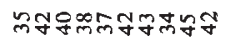 \\
\hline 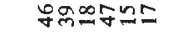 & 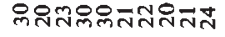 & สిసึజేస్గా & 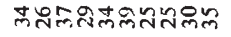 & 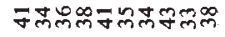 \\
\hline ๓๓m๒ & 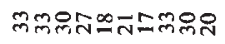 & ๓ニลสฺัส & 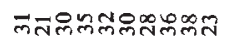 & 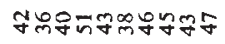 \\
\hline & ల & $\approx$ & m & $\bar{a}$ \\
\hline
\end{tabular}

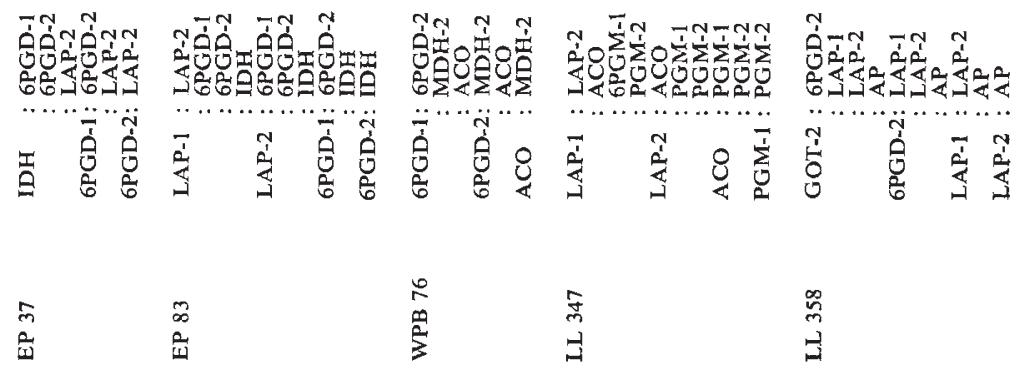


pair. But since recombination of 40 per cent or greater is undetectable with our level of replication, a rough estimate for the number of detectably linked pairs is 80 per cent of $1 \cdot 8$, or $1 \cdot 4$. This expectation is in general agreement with our results, which reveal one definitely linked pair and four other pairs possibly linked.

Two pairs of loci, LAP-2 and IDH, and LAP-1 and ACO, showed evidence of linkage in one tree, but conformed to a model of independent assortment when compared in a second tree. In both instances where these pairs of loci appeared to be linked, the recombination frequency was relatively high, 38-39 per cent, and sample sizes relatively small. Differences between trees in recombination frequency can be attributed to a variety of causes, the two most likely ones in this case being sampling error and inversion polymorphism (Saylor and Smith, 1966).

In view of the apparent tree-to-tree variation, it would appear desirable to secure estimates of recombination frequency from a number of trees for each pair of putatively-linked loci. At this time, only GPI-2 and GOT-1 appear to be tightly linked. Several other pairs of loci may also be linked, but it would be premature to consider them so without additional estimates from other trees. In the absence of suitable cytological markers, we cannot assign any linkage group to a specific chromosome or do simultaneous analyses of chromosomal and genic variation as is done in Drosophila. It should be possible in the future to secure estimates of gametic phase disequilibrium in conifers by analysing the same set of megagametophytes for these enzyme systems in large populations.

It is of interest that GPI-2 and GOT-1 also appear to be linked in ponderosa pine as noted earlier. These two species are placed in different sub-sections of the section Pinus (Critchfield and Little, 1966) which are not geographically contiguous. A reasonable estimate for the minimum time since divergence of these species' ancestors would be the end of the Pliocene epoch, and perhaps as early as the Miocene. It is widely presumed that conifers in general have been very conservative in their evolution. The fact that this pair of loci appears to be linked in two species separated for at least two million years supports this presumption. As additional loci in additional species are examined, it seems probable that such data will be useful in a systematics context.

These results are the first report of tight linkage in trees and represent a beginning in mapping the conifer genome. The use of allozymes and haploid gametophyte tissue can rapidly advance genetic knowledge in conifers and contribute to improvement through breeding.

Acknowledgments.-We thank Richard Beck for technical assistance during the course of this study. This work was supported by NSF grant DEB 74-1194 to F. T. L.

\section{REFERENCES}

BERGMANn, F. 1974. The genetics of some isoenzyme systems in spruce endosperm (Picea abies), Genetika 6, 353-360.

GLEGG, M. T., ALlARD, R. W., AND KAHLER, A. L. 1972. Is the gene the unit of selection? Evidence from two experimental plant populations. Proc. Nat. Acad. Sci. (USA), 69, 2474-2478.

GRITCHFIELD, W. B., AND litTle, E. L., JR. 1966. Geographic distribution of the pines of the world. USDA-Forest Service Misc. Publ. 991, p. 97. 
GREEN, M. C. 1970. Linkage map of the mouse (Mus musculus). In Handbook of Biochemistry, 2nd edition, ed. H. A. Sober. Chemical Rubber, Co., Cleveland.

GURIES, R. P., AND LEDIG, F. T. 1978. Inheritance of some polymorphic isoenzymes in pitch pine (Pinus rigida Mill.). Heredity 40, 27-32.

LALLEY, P. A. 1977. Human biochemical genetic map. Isozyme Bull., 10, 12-17.

LANGLEY, C. H., TOBARI, Y. N., AND KOJIMA, K. 1974. Linkage disequilibrium in natural populations of Drosophila melanogaster. Genetics, 78, 921-936.

Lundkvist, к. 1974. Analysis of linkage in Picea abies by means of isozyme studies. Proc. IUFRO Meeting, S.02.04.1-3, Stockholm, p. 468.

MACINTYRE, R. J., AND O'BRIEN, s. J. 1977. Biochemical loci of Drosophila melanogaster. Isozyme Bull., 10, 9-11.

NEUFFER, M. G., AND COE, E. H., JR. 1970. Linkage map and annotated list of genetic markers in maize linkage map of maize chromosomes. In Handbook of Biochemistry, 2nd edition, ed. H. A. Sober. Chemical Rubber Co., Cleveland.

sax, H. 1933. Chromosome number and morphology in the conifers. F. Arnold Arb., $14,356-375$.

SAYLOR, L. C., AND SMITH, B. W. 1966. Meiotic irregularity in species and interspecific hybrids of Pinus. Am. 7. Bot., 53, 453-468.

sCANDALIOS, J. G. 1969. Genetic control of multiple molecular forms of enzymes in plants: a review. Biochem. Genet., 31, 37-79.

SIMONSEN, V., AND WELLENDORF, H. 1975. Some polymorphic isoenzymes in the seed endosperm of Sitka spruce Picea sitchensis (Bond.) Carr.]. For. Tree Improv. 9. Arboretet Hørsholm, Akademisk Forlag, København, p. 20.

zoURos, E., KRIMBAs, c. B., TSAKAS, S., AND LOUKAs, M. 1974. Genic versus chromosomal variation in natural populations of Drosophila subobscura. Genetics, 78, 1223-1244. 